\title{
Special Issue on rib fixation
}

\author{
L. Leenen
}

Published online: 22 September 2010

(C) The Author(s) 2010. This article is published with open access at Springerlink.com

In this issue a controversial topic is brought to your attention. Fixation of the ribs and stabilization of the ribcage are topics that have been discussed for over a century, as the article of Bemelman [1] in this issue makes clear. Although thoracic trauma is responsible for $25 \%$ of the deaths resulting from trauma [2], only limited attention has been given to the subject over the years, aside from simple treatment like drainage. Operative management is required in only $10 \%$ of cases; usually in cases with major life-threatening thoracic injuries like aortic rupture and massive hemothorax. The treatment of flail chest is mostly limited to prolonged ventilator support, treating the underlying lung contusion and stabilizing the chest wall through internal splinting. However, this approach often incurs complications like ventilator-associated pneumonia. Treatment tends to be limited for rib fractures, although several studies have indicated that more than three rib fractures give rise to a twofold increase in the risk of dying from the chest injury, at least in patients over 45 years of age [3, 4].

An improved understanding of the biomechanics of the ribs [5] and the availability of newer implants that accommodate these features have prompted renewed interest in the fixation of ribs, both in the context of flail chest and in patients with rib fractures who are in heavy pain and for whom regional painkilling techniques like epidural analgesia have had limited success. Until now, limited experience and a lack of high-level evidence have led to fierce discussions about indications for rib stabilization.

With this in mind, this Special Issue brings you the historical perspective on rib fixation, new insights into the biomechanical aspects of ribs and rib fixation, as well as first experiences with this technique in the clinical arena.

Open Access This article is distributed under the terms of the Creative Commons Attribution Noncommercial License which permits any noncommercial use, distribution, and reproduction in any medium, provided the original author(s) and source are credited.

\section{References}

1. Bemelman M, Leenen LPH. Historic overview of fixation of rib fractures. Eur J Trauma Emerg Med. 2010.

2. Committee on Trauma American College of Surgeons, ATLS manual. 8th ed. Chicago; 2008.

3. Kent R, Woods W, Bostrom O. Fatality risk and the presence of rib fractures. Annu Proc Assoc Adv Automot Med. 2008;52:73-82.

4. Todd SR, McNally MM, Holcomb JB, Kozar RA, Kao LS, Gonzalez EA, Cocanour CS, Vercruysse GA, Lygas MH, Brasseaux BK, Moore FA. A multidisciplinary clinical pathway decreases rib fracture-associated infectious morbidity and mortality in high risk trauma patients. Am J Surg. 2006;192(6):806-11.

5. Mohr M, Abrams E, Engel C, Long WB, Bottlang M. Geometry of human ribs pertinent to oerthopedic chestwall reconstruction. J Biomech. 2007;40(6):1310-7.
L. Leenen $(\bowtie)$

Department of Surgery, UMC Utrecht, Utrecht, The Netherlands

e-mail: lleenen@umcutrecht.nl 